\title{
A new method of enhancing reliability for transmission expansion planning
}

\author{
Chengxin LI, Guo CHEN ( $₫)$, Junyong LIU
}

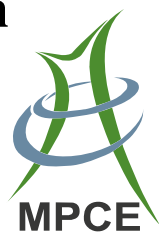

\begin{abstract}
The reliability plays a significant role in power systems and it is an important objective or constraint in transmission expansion planning. Firstly, a DC optimization model was proposed to calculate the maximum arrival power at each load point. Compared to the network flow method, DC model is closer to the actual power flow and it is able to obtain more realistic reliability assessment results. Furthermore, a novel sensitivity index (SI) was also proposed to choose the most effective line so as to enhance the nodal and/or system reliability. The Monte Carlo simulation is used to simulate the system components state. This improved reliability evaluation method and SI can be used for transmission expansion planning or maintenance scheduling. Tests are performed using 6-bus system derived from the Garver's system and the IEEE 10-machine 39-bus system. The results show the effectiveness of the method.
\end{abstract}

Keywords Probabilistic reliability evaluation, Sensitivity analysis, Monte Carlo simulation, DC model

\section{Introduction}

Transmission system plays a significant role in electric power system. It is not only a linkage between the generation

CrossCheck date: 13 November 2014

Received: 29 August 2014 / Accepted: 13 November 2014/Published online: 12 December 2014

(C) The Author(s) 2014 This article is published with open access at Springerlink.com

C. LI, J. LIU, The School of Electrical Engineering and Information, Sichuan University, Chengdu 610065, China

C. LI

e-mail: Lcx36@scu.edu.cn

G. CHEN, The School of Electrical and Information

Engineering, The University of Sydney, Camperdown,

NSW 2006, Australia

$(\bowtie)$ e-mail: guo.chen@sydney.edu.au and distribution, but also provides a non-discriminative and reliable environment for demanders and suppliers [1]. With the growth of load demand, the generation expansion planning (GEP) and transmission expansion planning (TEP) become more and more important. The main objective of TEP is to develop the system as economically as possible [2] due to the load growth, and it is subject to a set of economic, technical and reliability constraints $[1,3]$. In the regulated market, GEP and TEP are sub-tasks of a power system planning process performed by a regulated power utility. However, in the deregulated market environment, TEP is usually performed separately by transmission network service providers, while GEP becomes the task of generation companies or investors [4]. In the conventional monopolistic market, the power utilities have the social obligations to provide a reliable electricity supply. In a competitive market, the reliability of service is one of the important factors for market competitiveness [5, 6]. Therefore, a reliability level is an important constraint for TEP process. In addition, at the time of preparation for maintenance scheduling, a certain level of supplying reliability must be guaranteed after some power system components which are in outage and maintenance state $[7,8]$. Thus, reliability evaluation and reinforcement are very meaningful works both in the power system planning or maintenance scheduling.

Generally, power system reliability includes two aspects: adequacy and security. Adequacy measures the generation and transmission capacities of the system under static conditions, without considering system disturbances [3]. In this paper, the reliability means adequacy. It is not only restricted by the capacities of the generators and transmission lines, but also subjected to the availabilities of them. The reliability analysis is carried out before stability and fault analyses in conventional TEP [9]. Thus, reliability evaluation should be incorporated in TEP. Otherwise there is no guarantee to have a trustworthy supply for demands [3]. 
Generally, TEP problem can be formulated as an optimization problem. Reliability is generally treated as a constraint [10] or a part of objective function to deal with [11]. The common reliability of the system is often assumed to be guaranteed via the demand constraints. That is, these constraints enforce that line capacities exceed the line loads based on an assumed demand profile [12]. In [11], the probabilistic load curtailment loss was handled as a part of objective function and a TEP approach considering the load and wind power generation uncertainties was proposed. The different reliability indices such as loss of load expectation (LOLE) [13], loss of load probability (LOLP) [14], hierarchical reliability assessment [15], loss of load cost (LOLC) [16] and expected energy not supplied (EENS) [17] have been used to investigate TEP. Among them, LOLE and EENS are two common reliability indices and they are easily obtained from the load duration curve (LDC). An extended effective load model, considering the capacities and uncertainties of generators and transmission lines, has been proposed $[5,6]$. Then an extended nodal ELDC based on this extended effective load model can be obtained. Thus, the indices LOLE and EENS can be calculated.

Through reliability evaluation, if the system reliability indices do not satisfy the prescribed criteria, there is a reasonable question: where to add a transmission line is the most effective to improve the reliability indices. In [14], a method was developed for analyzing the reliability of composite power systems under the constraints of emissions. Some reliability indices are expressed by the function of the relevant factors such as the element forced outage rates (FOR) and the element capacities. Then their sensitivity with respect to various relevant factors are obtained by calculating the partial derivative of the reliability indices [14, 18-20]. A sensitivity index (SI) based constructive heuristic algorithm (CHA) has been applied for TEP [21, 22]. At each step of CHA, a component (circuit) of the feasible solutions must be added to the system. The choice of this component is determined by SI. The SI is based on the greatest active power flow of circuits, which is obtained from the solution to relaxing the integrality of DC investment model [21]. As an improvement, SI comes from the greatest apparent power flow of circuits, which is obtained from the solution to relaxing the integrality of AC investment model [22].

Following the previous work, this paper proposed a method to evaluate the composite power system reliability considering the FOR of the generators as well as the transmission lines. The Monte Carlo method is used to simulate the random behavior of the availability of the system components (generator or branch). A DC power flow model, instead of the network flow method [5, 6], is used to obtain more accurate maximum arrival power at load point. With the reliability evaluation process, an implicit sensitivity index based optimization method can be obtained, which can help to choose the most effective component so as to improve the system or bus reliability.

There are two main contributions of this paper. One is that the DC model optimization was used to improve the accuracy of maximum arrival power at each load point. The other one is that a novel SI based optimization method was presented to choose the most effective line so as to enhance the reliability.

The remainder of this paper is organized as follows. A DC model based reliability evaluation model of composite power system is presented in Section 2. Section 3 proposes the process of obtaining the ELDC using the Monte Carlo simulation and provides a sensitivity analysis index. Case studies are presented in Section 4. Finally, the paper is concluded in Section 5.

\section{Reliability evaluation model of composite power system}

The traditional ELDC considers only the FOR of the units, without the FOR of the transmission lines [5]. Firstly, a composite ELDC and the reliability indices LOLE and EENS [5, 6] are briefly introduced. Then, an optimization model of obtaining minimum outage power (i.e. maximum arrival power) at load point is presented, which is a DC constraint model.

\subsection{Model of reliability evaluation in composite power system}

The reliability indices, such as LOLE and EENS, can be assessed using a composite ELDC (CMELDC) based on the effective load model at the load point $[5,6]$. When a load point curtails a certain amount of load due to outages of generator unit and/or transmission line, it is equivalent to the case because the same amount of probabilistic loads is added to the load point but no components outage $[5,6,23]$. Base on this concept, the effective inverted load duration curve can be obtained at load point $k$.

$\Phi_{i}^{k}\left(x_{\mathrm{e}}\right)=\Phi_{i-1}^{k}\left(x_{\mathrm{e}}\right) \otimes f_{\mathrm{oi}}^{k}\left(x_{\mathrm{oi}}\right)=\int \Phi_{i-1}^{k}\left(x_{\mathrm{e}}-x_{\mathrm{oi}}\right) f_{\mathrm{oi}}^{k}\left(x_{\mathrm{oi}}\right) d x_{\mathrm{oi}}$

where $\otimes$ is the operator, indicating the convolution integral; $k$ is the load point number; $x_{\mathrm{e}}$ is the random variable of the effective load; $x_{\mathrm{oi}}$ is the random variable of the probabilistic load caused by the forced outage of component $i$; $\Phi_{i}^{k}\left(x_{\mathrm{e}}\right)$ is the effective inverted load duration curve caused by the forced outage of components 1 to $i$ at load 
point $k ; \Phi_{i-1}^{k}\left(x_{\mathrm{e}}\right)$ is the effective inverted load duration curve caused by the forced outage of components 1 to $i-1$ at load point $k ; f_{\mathrm{oi}}^{k}\left(x_{\mathrm{oi}}\right)$ is the probability density function (PDF) of the outage capacities caused by the forced outage of component $i$ at load point $k$.

From (1), it is important to note that $\Phi_{i}^{k}\left(x_{\mathrm{e}}\right)$ is calculated by iterative manner. If the total probability density function of the outage capacities caused by the forced outage of components 1 to $i$ at load point $k$ is determined, $\Phi_{i}^{k}\left(x_{\mathrm{e}}\right)$ can be obtained by (2).

$\Phi_{i}^{k}\left(x_{\mathrm{e}}\right)=\Phi_{0}^{k}\left(x_{\mathrm{e}}\right) \otimes f_{\mathrm{osi}}^{k}\left(x_{\mathrm{osi}}\right)=\int \Phi_{0}^{k}\left(x_{\mathrm{e}}-x_{\mathrm{osi}}\right) f_{\mathrm{osi}}^{k}\left(x_{\mathrm{osi}}\right) d x_{\mathrm{osi}}$

where $x_{\mathrm{osi}}$ is the random variable of the synthesized fictitious probabilistic load caused by the forced outage of components 1 to $i ; \Phi_{0}^{k}\left(x_{\mathrm{e}}\right)$ is the original inverted load duration curve at load point $k ; f_{\text {osi }}^{k}\left(x_{\text {osi }}\right)$ is the total probability density function of the outage capacities caused by the forced outage of components 1 to $i$ at load point $k$.

After obtaining the effective inverted load duration curve at load point, the reliability indices $L O L E_{k}$ and $E E N S_{k}$ can be calculated at load point $k$.

$$
\begin{aligned}
& \operatorname{LOLE}_{k}=\Phi_{N E}^{k}(x) \mid x=A P_{k} \\
& E_{E N S_{k}}=\int_{A P_{k}}^{A P_{k}+L_{\mathrm{P} k}} \Phi_{N E}^{k}(x) d x
\end{aligned}
$$

where $N E$ is the number of total elements (including generating units, transformer and transmission lines); $A P_{k}$ is the maximum arrival power at load point $k ; L_{P k}$ is the peak load at load point $k$.

The EENS of the entire system is equal to the summation of $E E N S_{k}$ at all load points, as shown in (5). However, the approach of calculating LOLE is completely different from the EENS. The expected load curtailed (ELC) at the load point $k$ must be calculated. Then, the ELC of the entire system can be obtained. Thus, the entire system LOLE index can be calculated.

$$
\begin{aligned}
& E E N S=\sum_{k=1}^{N D} E E N S_{k} \\
& E L C_{k}=E E N S_{k} / L O L E_{k} \\
& E L C=\sum_{k=1}^{N D} E L C_{k} \\
& L O L E=E E N S / E L C
\end{aligned}
$$

where $N D$ represents the number of load demand points.
2.2 Minimum outage power using DC model

To obtain the probability density function of the outage capacities caused by the forced outage of components, the load point outage power must be calculated first of all. There are several possible solutions when calculating the load point outage power for each component state. This problem can be formulated as an optimization model. The objective function for minimum outage power can be set up and an optimal solution can be obtained by the network flow method [5]. The network flow method takes into account Kirchhoff's current law (KCL) [24] at all nodes but neglecting Kirchhoff's voltage law (KVL) [25]. Thus, its accuracy is low. In this paper, transmission network is characterized by a simplified lossless DC load flow model. It not only satisfies KCL but also obeys Ohm's law. Thus, KVL is implicitly taken into account. Therefore, DC load flow model is more close to the actual situation and can improve the accuracy.

To minimize the outage power at load point, the mathematical model used to minimize the outage power at load point can be formulated as follows.

$\sum_{i=1}^{N D}\left(L_{\mathrm{p} i}-P_{\mathrm{L} i}\right) / L_{\mathrm{p} i}$

where $L_{\mathrm{p} i}$ is the peak load at bus $i ; P_{\mathrm{L} i}$ is the decision variable meaning effective supplied power at bus $i$ (therefore, they represent the arrival power at load point $i$ ).

Subject to

1) Power balance constraint at each node

$P_{\mathrm{G} i}-P_{\mathrm{L} i}=\sum_{j=1}^{n} P_{i j}$

where $P_{\mathrm{G} i}$ is the generation capacity at bus $i ; P_{i j}$ is the power flow between bus $i$ and $j ; n$ is the number of transmission lines connected to bus $i$.

2) Constraint of line power

$P_{i j}=b_{i j}\left(\theta_{i}-\theta_{j}\right)$

where $b_{i j}$ is the susceptance of the transmission lines between bus $i$ and $j ; \theta_{i}$ is the phase angle at bus $i$.

3) Limitation constraint of peak load

$0 \leq P_{\mathrm{L} i} \leq L_{\mathrm{P} i}$

4) Limitation constraint of generation capacity

$0 \leq P_{\mathrm{G} i} \leq P_{\mathrm{G} i}^{\max }$

where $P_{\mathrm{G} i}^{\max }$ is the maximum capacity of generation at bus $i$. 5) Limitation constraint of transmission capacity

$-P_{i j}^{\max } \leq P_{i j} \leq P_{i j}^{\max }$ 
where $P_{i j}^{\max }$ is the maximum transmission capacity between bus $i$ and $j$.

\section{Probabilistic reliability evaluation and sensitivity analysis}

\subsection{State probability calculation}

There are two fundamental methods for probabilistic reliability evaluation: state enumeration and Monte Carlo simulation $[2,26]$. Generally, if the outage probabilities of most of the components are very small (i.e. the system is reliable) or the number of components is very small, state enumeration method is usually more efficient. When the complex operating conditions are concerned or outage probabilities of most of the components cannot be ignored, it is almost impossible to enumerate all the system states. Thus, Monte Carlo simulation is an effective alternative to obtain all the approximate system states.

Monte Carlo simulation method treats the problem as a series of experiments. Generally, generator states are modeled using multiple state random variables. In this paper, for simplicity, the generating units are taken into account and their states are modeled using two-state (up and down) random variables as well as transmission circuit states. It is assumed that component outages are mutually independent events. Therefore, transmission line and generating unit outages are simulated by separate random numbers.

In a planning context, the probability is a measure of the likelihood that the power system will be in a given situation at a random time in the future, and it is also a function of the availability of every piece of equipment in the power system. This relationship can be represented as follows [27].

$$
\begin{aligned}
\text { PRO } & =\prod_{i \in \mathbf{U}} u\left(c_{i}\right) \prod_{j \in \mathbf{A}} a\left(c_{j}\right) \\
& =\underbrace{u\left(c_{1}\right) u\left(c_{2}\right) \ldots u\left(c_{n}\right)}_{\text {Unavailable }} \underbrace{a\left(c_{1}\right) a\left(c_{2}\right) \ldots a\left(c_{m}\right)}_{\text {Available }}
\end{aligned}
$$

where $\mathbf{U}$ is the set of unavailable components; $\mathbf{A}$ is the set of available components.

Forced outage rate (FOR) of power system elements can be obtained through the historical data statistical method. Suppose that there are $N E$ elements including such as generation units, transmission lines, transformers. The random number generation method can generate a series of random numbers $y_{i}(i=1,2, \ldots, N E)$ distributed uniformly under $\{0,1\} . s_{i}$ is the state of component $i$ and $F O R_{i}$ is its forced outage rate. $s_{i}$ is expressed as (11). $s_{i}=\left\{\begin{array}{l}0\left(\text { normal state }, y_{i}>F O R_{i}\right) \\ 1\left(\text { abnormal state }, 0 \leq y_{i} \leq F O R_{i}\right)\end{array}\right.$

The state of all components can be formulated by a vector $\mathbf{S}$ as (12).

$\mathbf{S}=\left[s_{1}, s_{2}, \ldots, s_{i}, \ldots s_{N E}\right]$

The probability of component $i$ appearing the state $s_{i}$ can be expressed as follows.

$P R O\left(s_{i}\right)=s_{i} F O R_{i}+\left(1-s_{i}\right)\left(1-F O R_{i}\right)$

According to (10), the probability of the state vector $\mathbf{S}$, $\operatorname{PRO}(\mathbf{S})$, is calculated as (14).

$P R O(\mathbf{S})=\prod_{i=1}^{N E} P\left(s_{i}\right)$

It is assumed that the system states are sampled $N$ times. If $N$ is large enough, the state combinations of all the system components can be sampled. The component state vector $\mathbf{S}$ may be the same in the $N$ times samples. After removing duplicate state $\mathbf{S}$, a state set $U(\mathbf{S})$ of all the system components and the corresponding probability values can be obtained.

\subsection{Sensitivity index}

The reliability indices are not only associated with the capacity of each component, but also related to the FOR. The sensitivity index (SI) based DC model [21] or AC model [22] does not consider the FOR of the component. The indices LOLE and EENS are strongly associated with the arrival power at load point. Therefore, based on the Monte Carlo simulation and the optimization model shown as (9), an implicit sensitivity index is presented.

Generally, at the initial stage of planning, human knowledge is needed to ensure rationality of the candidate line selection with practical engineering and management concerns [28]. The main focus of this paper is on the reliability evaluation and its sensitivity analysis. Therefore, it is assumed that the feasible candidate pool of transmission lines has been obtained properly. Assuming the candidate pool is expressed as follows.

$\mathbf{X}=\left\{x_{1}, x_{2}, \ldots, x_{N C}\right\}$

where $N C$ is the number of candidate transmission lines.

The state of all components can be expressed as a vector $\mathbf{S}$, and its corresponding probability can be calculated, shown as (12) and (14), respectively. Under the state $\mathbf{S}$, the arrival power vector $\boldsymbol{A P}_{k}(k=1,2, \ldots, N D)$ at each load point can be obtained using the model (9) first of all. Next, assuming that one candidate line $x_{i}(i=1,2, \ldots, N C)$ is added to the power grid and then the corresponding arrival power vector $\boldsymbol{A P}_{k}^{i}$ at each load point can be obtained using 
the model (9) again. Thus, the incremental vector of the arrival power at each load point, caused by adding the line $x_{i}$, can be easily calculated as (16).

$\Delta \boldsymbol{A} \boldsymbol{P}_{k}^{i}=\boldsymbol{A} \boldsymbol{P}_{k}^{i}-\boldsymbol{A} \boldsymbol{P}_{k}$

Due to the fact that the different system state has different probability, the above $\Delta \boldsymbol{A} \boldsymbol{P}_{k}^{i}$ should be taken into account with its system state probability. The incremental of the arrival power under the state probability, denoted as $\Delta \boldsymbol{P}_{k}^{i}$, can be expressed as (17).

$\Delta \boldsymbol{P}_{k}^{i}=P R O(\mathbf{S}) \Delta \boldsymbol{A} \boldsymbol{P}_{k}^{i}$

Next, each of candidate lines is in turn added to the grid to get the corresponding incremental vector of the arrival power under the state probability. Then, the incremental arrival power matrix $\Delta \boldsymbol{P}$ under the current system state due to adding each of candidate lines to the gird is shown in (18).

$\Delta \boldsymbol{P}=\left[\begin{array}{c}\Delta \boldsymbol{P}_{k}^{1} \\ \vdots \\ \Delta \boldsymbol{P}_{k}^{N C}\end{array}\right]=\left[\begin{array}{ccc}\Delta P_{1}^{1} & \cdots & \Delta P_{N D}^{1} \\ \vdots & \vdots & \vdots \\ \Delta P_{1}^{N C} & \cdots & \Delta P_{N D}^{N C}\end{array}\right]$

For each state in the state set $U(\mathbf{S})$, the above calculating process of obtaining $\Delta \boldsymbol{P}$ is repeated. Every time, the obtained incremental arrival power matrix $\Delta \boldsymbol{P}$ is accumulated.

Finally, the sensitivity index for the entire system and for load point $k$ can be calculated using (19) and (20), respectively.

$$
\begin{aligned}
S I_{\mathrm{sys}} & =\max \left\{S I_{x_{i}}=\sum_{k=1}^{N D} \Delta \boldsymbol{P}_{k}^{i},(i=1,2, \ldots, N C)\right\} \\
S I_{\mathrm{Bus}}^{k} & =\max \left\{S I_{x_{i}}^{k}=\Delta \boldsymbol{P}_{k}^{i},(i=1,2, \cdots, N C)\right\}(k \\
& =1,2, \ldots, N D)
\end{aligned}
$$

\subsection{The main procedure of reliability evaluation}

As discussed above, reliability evaluation starts with Monte Carlo simulation to obtain the system components state set $U(\mathbf{S})$. Then, for a state $\mathbf{S}$, the arrival power at each load point can be obtained using the DC constraint optimization algorithm. At the same time, the incremental arrival power matrix $\boldsymbol{\Delta P}$ due to in turn adding one candidate line into grid can be gained too. Next, this calculating procedure is repeated until each state in state set $U(\mathbf{S})$ has been dealt with. Then, the probability density function of the outage power at each load point and the accumulated matrix $\Delta \boldsymbol{P}$ are obtained. Thus, the effective LDC at each load point can be achieved by calculating the convolution of the original inverted duration curve at load point and the pdf of the outage

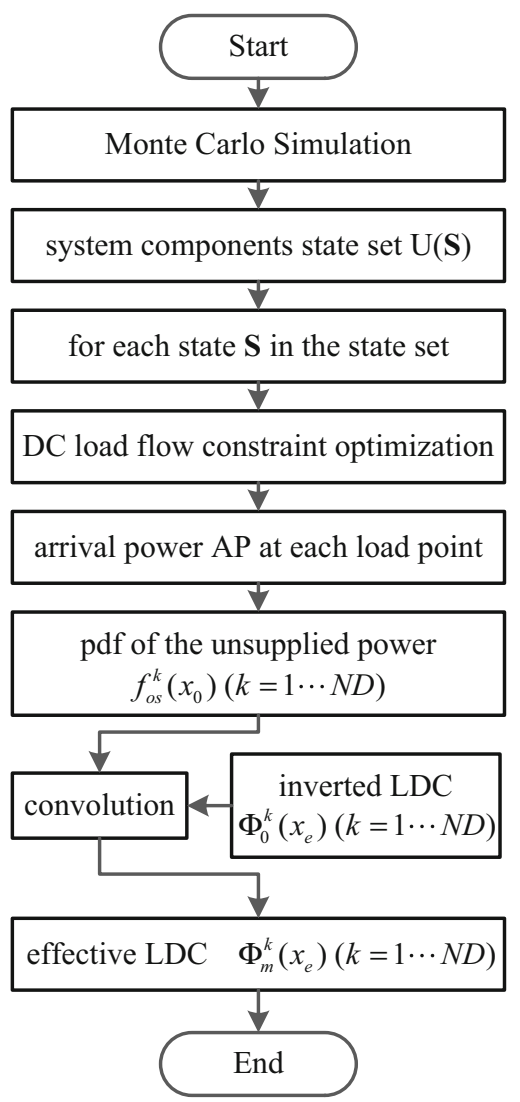

Fig. 1 Main procedure of obtaining the effective LDC

capacities. The main procedure of obtaining the effective LDC is shown in Fig. 1.

Next, the load bus reliability indices can be calculated according to (3) and (4), and the system reliability indices can be calculated according to (5)-(8). Moreover, the system and bus reliability indices can be augmented by adding the grid each time a line which is based on rules (19) and (20), respectively.

\section{Case studies}

The proposed method is tested on Garver's 6-bus system and IEEE 39-bus model system. The algorithm was implemented in Matlab 8.2, using a PC with Core i7-4770 CPU clocking at $3.4 \mathrm{GHz}$ and $32 \mathrm{~GB}$ of RAM. The DC constraint optimization is solved using the YAMIP environment [29]. In the two cases, it is assumed that the inverted LDC of load point is a polyline, shown as in Fig. 2.

\subsection{Garver's 6-bus system}

This system has 6 buses and a demand of 760 MW [24]. The line data in [24] are remained unchanged. The load 


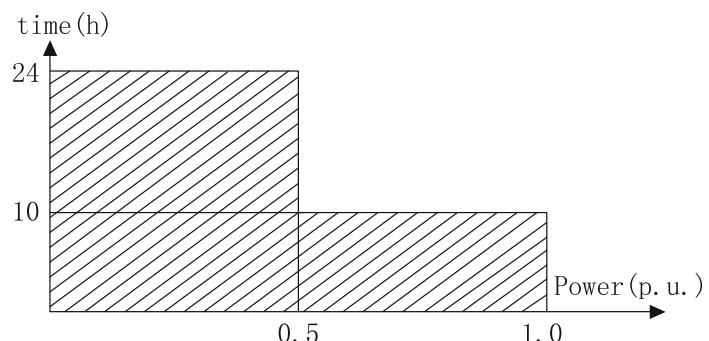

Fig. 2 Inverted load duration curve at load point

Table 1 Load and generation data for 6-bus system

\begin{tabular}{lrl}
\hline Bus number & Load (MW) & Units (MW) \\
\hline 1 & 80 & 50 \\
2 & 245 & 0 \\
3 & 40 & $3 \times 85$ \\
4 & 160 & 0 \\
5 & 235 & 0 \\
6 & 0 & $7 \times 100$ \\
\hline
\end{tabular}

data and generator data are provided in Table 1. The generator is expressed using units due to the request for considering the FOR of the components. To exclude the impact on the reliability due to generator outage, the generator capacities are expanded.

The current system structure is shown in Fig. 3. For simplicity, FORs of all transmission lines and generating units are set to $0.5 \%$ and $1 \%$, respectively.

Monte Carlo simulation method is used for state simulation. The reliability indices at the load points are evaluated using the proposed method and the results are shown in Table 2. Thus, the system reliability indices EENS and LOLE are calculated by (5) and (8), respectively. The system reliability indices are shown in Table 2 at last row.

Suppose that the candidate pool of transmission lines consists of the current transmission corridors, which have 8 right-of-way lines, shown in Table 3.

The incremental arrival power matrix $\boldsymbol{\Delta} \boldsymbol{P}$ by adding each candidate line is as follows.

$$
\Delta \boldsymbol{P}=\left[\begin{array}{ccccc}
0 & -1.3212 & 0 & 0.6705 & 42.3723 \\
0 & 2.3933 & 0 & -7.2632 & -7.3073 \\
0 & 0.0351 & 0 & -2.3649 & 33.1669 \\
0 & -0.9488 & 0 & -1.5299 & -25.3088 \\
0 & 0.0457 & 0 & 13.6963 & 4.6497 \\
0 & 3.1280 & 0 & 13.9975 & 1.7246 \\
0 & -0.5101 & 0 & -3.8953 & 113.4931 \\
0 & 1.6323 & 0 & 48.5670 & 38.5338
\end{array}\right]
$$

According to Table 2, the load point with the maximum EENS and LOLE is the bus 5. From (21), it can be found that the bus sensitivity index at bus 5 is $S I_{\text {Bus }}^{5}=$

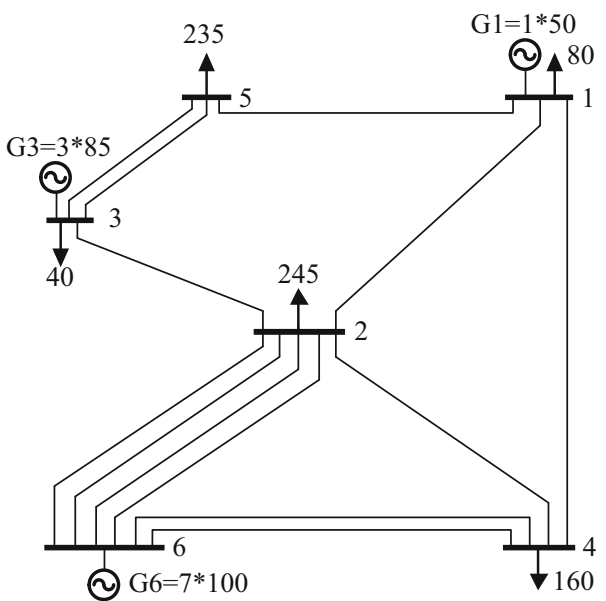

Fig. 3 The 6-bus system derived from the Garver's system

Table 2 Reliability indices of the base case

\begin{tabular}{lccc}
\hline $\begin{array}{l}\text { Load bus } \\
\text { number }\end{array}$ & $\begin{array}{l}\text { EENS } \\
\text { (MWh/year) }\end{array}$ & $\begin{array}{l}\text { LOLE } \\
\text { (h/year) }\end{array}$ & $\begin{array}{l}\text { ELC } \\
\text { (MW/year) }\end{array}$ \\
\hline 1 & 0 & 0 & 0 \\
2 & 120.7 & 2.5827 & 46.73 \\
3 & 0 & 0 & 0 \\
4 & 1777.1 & 38.72 & 45.90 \\
5 & 4243.6 & 143.91 & 29.49 \\
System & 6141.4 & 50.29 & 122.12 \\
\hline
\end{tabular}

$(S I)_{x 7}^{5}=113.4931$, and the corresponding candidate line is line 7 (line $3-5$ ). The system sensitivity index is $S I_{\mathrm{sys}}=S I_{x 7}=$ 109.1877 and the corresponding candidate line is also line 7 .

The line 7 (line $3-5$ ) is added to the grid and the reliability indices are evaluated again using the proposed method. The evaluation results are shown in Table 4.

From Table 4, it can be seen that the reliability indices of system and bus 5 have been greatly improved, after adding line 3-5 $_{5}$ to the gird.

\subsection{9-bus system}

In this case, the proposed method is tested on NewEngland 10-machine 39-bus system, shown as in Fig. 4. The system data, shown in Table 5 and Table 6, are taken from the open source software Matpower 4.1 [30]. In Table 5, $N L$ represents the number of Line; FB and TB are from and to buses of the line, respectively; and X stands for the reactance of the line.

After Monte Carlo simulation sampling times of $10^{5}$, the load point ELDCs are obtained and the reliability indices are followed to be evaluated. For simplicity, the zero results are ignored and non-zero parts are shown in 
Table 3 Candidate pool of transmission lines

\begin{tabular}{llllll}
\hline $\begin{array}{l}\text { Line } \\
\text { number }\end{array}$ & $\begin{array}{l}\text { From } \\
\text { bus }\end{array}$ & To bus & $\begin{array}{l}\text { Line } \\
\text { number }\end{array}$ & $\begin{array}{l}\text { From } \\
\text { bus }\end{array}$ & To bus \\
\hline 1 & 1 & 2 & 5 & 2 & 4 \\
2 & 1 & 4 & 6 & 2 & 6 \\
3 & 1 & 5 & 7 & 3 & 5 \\
4 & 2 & 3 & 8 & 4 & 6 \\
\hline
\end{tabular}

Table 4 Reliability indices after adding line ${ }_{3-5}$ to the gird

\begin{tabular}{lccc}
\hline $\begin{array}{l}\text { Load } \\
\text { busnumber }\end{array}$ & $\begin{array}{l}\text { EENS (MWh/ } \\
\text { year) }\end{array}$ & $\begin{array}{l}\text { LOLE (hours/ } \\
\text { year] }\end{array}$ & $\begin{array}{l}\text { ELC (MW/ } \\
\text { year) }\end{array}$ \\
\hline 1 & 0 & 0 & 0 \\
2 & 139.3 & 3.28 & 42.51 \\
3 & 0 & 0 & 0 \\
4 & 1917.7 & 36.07 & 53.17 \\
5 & 87.6 & 3.80 & 23.04 \\
System & 2147.6 & 18.06 & 118.73 \\
\hline
\end{tabular}

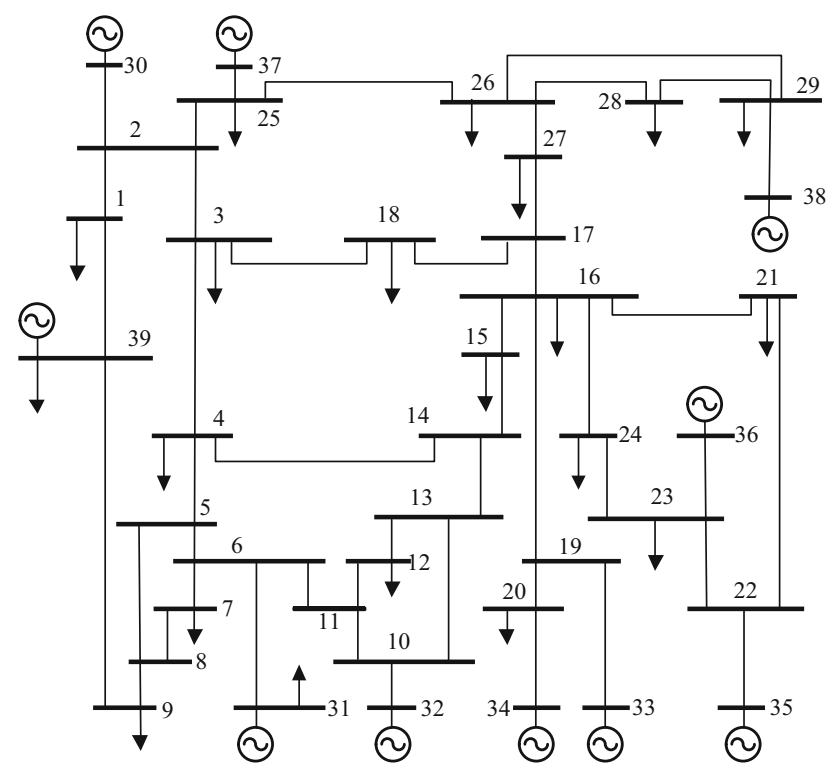

Fig. 4 The New-England 10-machine39-bus system

Table 7. The corresponding sensitivity indices are calculated and shown in the last column of Table 7.

From Table 7, it can be seen that bus 39 has the maximum EENS and adding the line 1 (from bus 1 to bus 2 ) is the most effective for increasing the reliability of bus 39 .

However, adding the line 3 (from bus 2 to bus 3 ) is the most effective measures for increasing the system reliability. After adding the line 1, we can get the new reliability indices results, shown as in Table 8 .
Table 5 Branch data for 39-bus system

\begin{tabular}{lrrlc|rrrrr}
\hline$N L$ & FB & TB & $\begin{array}{l}\text { X } \\
\text { (p.u.) }\end{array}$ & $\begin{array}{c}P \max \\
(\mathrm{MW})\end{array}$ & $N L$ & FB & TB & $\begin{array}{l}\text { X } \\
\text { (p.u.) }\end{array}$ & $\begin{array}{l}P \max \\
(\mathrm{MW})\end{array}$ \\
\hline 1 & 1 & 2 & 0.0411 & 600 & 24 & 14 & 15 & 0.0217 & 600 \\
2 & 1 & 39 & 0.0250 & 1000 & 25 & 15 & 16 & 0.0094 & 600 \\
3 & 2 & 3 & 0.0151 & 500 & 26 & 16 & 17 & 0.0089 & 600 \\
4 & 2 & 25 & 0.0086 & 500 & 27 & 16 & 19 & 0.0195 & 600 \\
5 & 2 & 30 & 0.0181 & 900 & 28 & 16 & 21 & 0.0135 & 600 \\
6 & 3 & 4 & 0.0213 & 500 & 29 & 16 & 24 & 0.0059 & 600 \\
7 & 3 & 18 & 0.0133 & 500 & 30 & 17 & 18 & 0.0082 & 600 \\
8 & 4 & 5 & 0.0128 & 600 & 31 & 17 & 27 & 0.0173 & 600 \\
9 & 4 & 14 & 0.0129 & 500 & 32 & 19 & 20 & 0.0138 & 900 \\
10 & 5 & 6 & 0.0026 & 1200 & 33 & 19 & 33 & 0.0142 & 900 \\
11 & 5 & 8 & 0.0112 & 900 & 34 & 20 & 34 & 0.0180 & 900 \\
12 & 6 & 7 & 0.0092 & 900 & 35 & 21 & 22 & 0.0140 & 900 \\
13 & 6 & 11 & 0.0082 & 480 & 36 & 22 & 23 & 0.0096 & 600 \\
14 & 6 & 31 & 0.0250 & 1800 & 37 & 22 & 35 & 0.0143 & 900 \\
15 & 7 & 8 & 0.0046 & 900 & 38 & 23 & 24 & 0.0350 & 600 \\
16 & 8 & 9 & 0.0363 & 900 & 39 & 23 & 36 & 0.0272 & 900 \\
17 & 9 & 39 & 0.0250 & 900 & 40 & 25 & 26 & 0.0323 & 600 \\
18 & 10 & 11 & 0.0043 & 600 & 41 & 25 & 37 & 0.0232 & 900 \\
19 & 10 & 13 & 0.0043 & 600 & 42 & 26 & 27 & 0.0147 & 600 \\
20 & 10 & 32 & 0.0200 & 900 & 43 & 26 & 28 & 0.0474 & 600 \\
21 & 11 & 12 & 0.0435 & 500 & 44 & 26 & 29 & 0.0625 & 600 \\
22 & 12 & 13 & 0.0435 & 500 & 45 & 28 & 29 & 0.0151 & 600 \\
23 & 13 & 14 & 0.0101 & 600 & 46 & 29 & 38 & 0.0156 & 1200 \\
\hline & & & & & & & & &
\end{tabular}

Table 6 Load and generation data for 39-bus system

\begin{tabular}{|c|c|c|c|c|c|}
\hline $\begin{array}{l}\text { Bus } \\
\text { number }\end{array}$ & $\begin{array}{l}\text { Load } \\
\text { (MW) }\end{array}$ & $\begin{array}{l}\text { Generation } \\
\text { (MW) }\end{array}$ & $\begin{array}{l}\text { Bus } \\
\text { number }\end{array}$ & $\begin{array}{l}\text { Load } \\
\text { (MW) }\end{array}$ & $\begin{array}{l}\text { Generation } \\
\text { (MW) }\end{array}$ \\
\hline 1 & 97.6 & 0 & 21 & 274 & 0 \\
\hline 2 & 0 & 0 & 22 & 0 & 0 \\
\hline 3 & 322 & 0 & 23 & 247.5 & 0 \\
\hline 4 & 500 & 0 & 24 & 308.6 & 0 \\
\hline 5 & 0 & 0 & 25 & 224 & 0 \\
\hline 6 & 0 & 0 & 26 & 139 & 0 \\
\hline 7 & 233.8 & 0 & 27 & 281 & 0 \\
\hline 8 & 522 & 0 & 28 & 206 & 0 \\
\hline 9 & 6.5 & 0 & 29 & 283.5 & 0 \\
\hline 10 & 0 & 0 & 30 & 0 & 1040 \\
\hline 11 & 0 & 0 & 31 & 9.2 & 646 \\
\hline 12 & 8.53 & 0 & 32 & 0 & 725 \\
\hline 13 & 0 & 0 & 33 & 0 & 652 \\
\hline 14 & 0 & 0 & 34 & 0 & 508 \\
\hline 15 & 320 & 0 & 35 & 0 & 687 \\
\hline 16 & 329 & 0 & 36 & 0 & 580 \\
\hline 17 & 0 & 0 & 37 & 0 & 564 \\
\hline 18 & 158 & 0 & 38 & 0 & 865 \\
\hline 19 & 0 & 0 & 39 & 1104 & 1100 \\
\hline 20 & 680 & 0 & & & \\
\hline
\end{tabular}


Table 7 Reliability indices and SI of the 39-bus system (non-zero parts)

\begin{tabular}{lcrcc}
\hline $\begin{array}{l}\text { Load bus } \\
\text { number }\end{array}$ & $\begin{array}{l}\text { EENS } \\
\text { (MWh/year) }\end{array}$ & $\begin{array}{l}\text { LOLE } \\
\text { (h/year) }\end{array}$ & \multicolumn{1}{l}{$\begin{array}{l}\text { ELC } \\
\text { (MW/year) }\end{array}$} & \multicolumn{1}{l}{ SI } \\
\hline 4 & 809.8 & 6.60 & 122.59 & $0.1806\left(\right.$ line $\left._{3}\right)$ \\
8 & 73.5 & 0.74 & 98.84 & $0.0158\left(\right.$ line $\left._{3}\right)$ \\
18 & 17.8 & 0.16 & 111.92 & $0.0029\left(\right.$ line $\left._{7}\right)$ \\
20 & 27096.9 & 235.71 & 114.96 & $6.2797\left(\right.$ line $\left._{3}\right)$ \\
25 & 86.1 & 0.96 & 89.45 & $0.0170\left(\right.$ line $\left._{4}\right)$ \\
27 & 1.7 & 0.07 & 26.00 & $0.0050\left(\right.$ line $\left._{31}\right)$ \\
29 & 31.7 & 0.16 & 199.79 & $0.0051\left(\right.$ line $\left._{46}\right)$ \\
31 & 2.1 & 0.32 & 6.52 & $0.0030\left(\right.$ line $\left._{14}\right)$ \\
39 & 47209.7 & 171.16 & 275.82 & $10.7070\left(\right.$ line $\left._{1}\right)$ \\
System & 75329.3 & 72.02 & 1045.89 & $15.6973\left(\right.$ line $\left._{3}\right)$ \\
\hline
\end{tabular}

Table 8 Reliability indices and SI of the 39-bus system, after adding line $_{1}$ (non-zero parts)

\begin{tabular}{lrrrr}
\hline $\begin{array}{l}\text { Load bus } \\
\text { number }\end{array}$ & $\begin{array}{l}\text { EENS } \\
\text { (MWh/year) }\end{array}$ & $\begin{array}{l}\text { LOLE } \\
\text { (h/year) }\end{array}$ & \multicolumn{1}{l}{$\begin{array}{l}\text { ELC } \\
\text { (MW/ } \\
\text { year) }\end{array}$} & \multicolumn{1}{l}{ SI } \\
\hline 4 & 7302.6 & 93.73 & 77.91 & $0.1806\left(\right.$ line $\left._{3}\right)$ \\
8 & 6976.3 & 43.72 & 159.58 & $0.0158\left(\right.$ line $\left._{3}\right)$ \\
18 & 17.7 & 0.16 & 111.92 & $0.0029\left(\right.$ line $\left._{7}\right)$ \\
20 & 23806.7 & 193.88 & 122.79 & $6.2797\left(\right.$ line $\left._{3}\right)$ \\
25 & 99.5 & 1.12 & 89.17 & $0.0170\left(\right.$ line $\left._{4}\right)$ \\
27 & 6.9 & 0.26 & 26.00 & $0.0050\left(\right.$ line $\left._{31}\right)$ \\
29 & 128.9 & 0.70 & 183.41 & $0.0051\left(\right.$ line $\left._{46}\right)$ \\
39 & 12550.1 & 34.69 & 361.79 & $10.7070\left(\right.$ line $\left._{1}\right)$ \\
System & 50888.7 & 44.93 & 1132.57 & $15.6973\left(\right.$ line $\left._{3}\right)$ \\
\hline
\end{tabular}

Comparing Table 8 with Table 7 , it is interesting to note that adding line 1 greatly improves the reliability at the bus 39 and thus increases the system reliability, as well as decrease the reliability at some other buses (such as bus 4 and 8). The reason is that adding the line changes the system structure and then changes the power flow.

\section{Conclusion}

This paper addresses the reliability evaluation problem considering the forced outage rates of generators and transmission lines. Based on the works in $[5,6]$, the DC power flow model are used to obtain more accurate maximum arrival power for more accurate reliability indices. The system components states are simulated using Monte Carlo technique first of all. Next, the probability density functions of the outage capacities at load buses are obtained through calculating the maximum arrival power using DC model based optimization under all possible system states. Then, the effective load duration curves at every load bus are obtained and the reliability indices can be calculated. With the reliability evaluation process, the implicit sensitivity indices of the reliability can be obtained, which help to choose the most effective component to improve the reliability of the system or a load bus. The work is an important step in preparing a transmission expansion plan or maintenance scheduling employing probabilistic reliability evaluation methods to ensure the reliability of the electric power grid.

Acknowledgments This work is supported by China Scholarship Council, as well as Young Teacher Scientific Research Foundation of Sichuan University (No. 2012SCU11003).

Open Access This article is distributed under the terms of the Creative Commons Attribution License which permits any use, distribution, and reproduction in any medium, provided the original author(s) and the source are credited.

\section{References}

[1] Lee CW, Ng SKK, Zhong J et al (2006) Transmission expansion planning from past to future. In: Proceedings of the 2005 IEEE PES power systems conference and exposition (PSCE'06), Atlanta, GA, 29 Oct-1 Nov 2006, pp 257-265

[2] Li WY, Choudhury P (2007) Probabilistic transmission planning. IEEE Power Energ Mag 5(5):46-53

[3] Hemmati R, Hooshmand RA, Khodabakhshian A (2013) Comprehensive review of generation and transmission expansion planning. IET Gener Transm Distrib 7(9):955-964

[4] Zhao JH, Foster J, Dong ZY et al (2011) Flexible transmission network planning considering distributed generation impacts. IEEE Trans Power Syst 26(3):1434-1443

[5] Choi J, Billinton R, Futuhi-Firuzabed M (2005) Development of a new nodal effective load model considering of transmission system element unavailabilities. IEE Proc Gener Transm Distrib 152(1):79-89

[6] Choi J, Tran T, El-Keib AA et al (2005) A method for transmission system expansion planning considering probabilistic reliability criteria. IEEE Trans Power Syst 20(3):1606-1615

[7] Ekpenyong UE, Zhang JF, Xia XH (2012) An improved robust model for generator maintenance scheduling. Electr Power Syst Res 92:29-36

[8] Zhang DB, Li WY, Xiong XF (2012) Bidding based generator maintenance scheduling with triple-objective optimization. Electr Power Syst Res 93:127-134

[9] Choi J, Mount TD, Thomas RJ (2007) Transmission expansion planning using contingency criteria. IEEE Trans Power Syst 22(4):2249-2261

[10] da Rochaa MC, Saraivab JT (2012) A multiyear dynamic transmission expansion planning model using a discrete based EPSO approach. Electr Power Syst Res 93:83-92

[11] Orfanos GA, Georgilakis PS, Hatziargyriou ND (2013) Transmission expansion planning of systems with increasing wind power integration. IEEE Trans Power Syst 28(2):1355-1362

[12] Shortle J, Rebennack S, Glover FW (2014) Transmissioncapacity expansion for minimizing blackout probabilities. IEEE Trans Power Syst 29(1):43-52 
[13] Shalash NA, Bin Ahmad AZ (2014) Agents for fuzzy indices of reliability power system with uncertainty using Monte Carlo algorithm. In: Proceedings of the IEEE 8th international power engineering and optimization conference (PEOCO'14), Langkawi, 24-25 Mar 2014, pp 258-264

[14] Benidris M, Mitra J (2014) Reliability and sensitivity analysis of composite power systems under emission constraints. IEEE Trans Power Syst 29(1):404-412

[15] Alizadeh B, Jadid S (2011) Reliability constrained coordination of generation and transmission expansion planning in power systems using mixed integer programming. IET Gener Transm Distrib 5(9):948-960

[16] da Silva AML, Rezende LS, Manso LAF et al (2010) Transmission expansion planning: A discussion on reliability and "N-1" security criteria. In: Proceedings of the IEEE 11th international conference on probabilistic methods applied to power systems (PMAPS'10), Singapore, 14-17 Jun 2010, pp 244-251

[17] Aghaei J, Amjady N, Baharvandi A et al (2014) Generation and transmission expansion planning: MILP-based probabilistic model. IEEE Trans Power Syst 29(4):1592-1601

[18] Sharaf TAM, Berg GJ (1982) Reliability optimization for transmission expansion planning. IEEE Trans Power App Syst 101(7):2243-2248

[19] Sharaf TAM, Berg GJ (1988) Reliability evaluation in powersystem transmission planning: Practical considerations. IEEE Trans Reliab 37(3):274-279

[20] Zhao Y, Zhou NC, Zhou JQ et al (2006) Research on sensitivity analysis for composite generation and transmission system reliability evaluation. In: Proceedings of the international conference on power system technology (PowerCon'06), Chongqing, 22-26 Oct 2006, 5 pp

[21] Sánchez IG, Romero R, Mantovani JRS et al (2005) Transmission-expansion planning using the DC model and nonlinearprogramming technique. IEE Proc Gener Transm Distrib 152(6):763-769

[22] Rider MJ, Garcia AV, Romero R (2007) Power system transmission network expansion planning using AC model. IET Gener Transm Distrib 1(5):731-742

[23] Sullivan RL (1977) Power system planning. McGraw-Hill, New York

[24] Romero R, Monticelli A, Garcia A et al (2002) Test systems and mathematical models for transmission network expansion planning. IEE Proc Gener Transm Distrib 149(1):27-36

[25] Jabr RA (2013) Optimization of AC transmission system planning. IEEE Trans Power Syst 28(3):2779-2787
[26] Li WY (2005) Risk assessment of power systems: Models, methods, and applications. IEEE Press, Piscataway

[27] EPRI (2003) Moving toward probabilistic reliability assessment methods: A framework for addressing uncertainty in power system planning and operation. EPRI Technical Results 1002639, Palo Alto

[28] Xu Z, Dong ZY, Wong KP (2006) A hybrid planning method for transmission networks in a deregulated environment. IEEE Trans Power Syst 21(2):925-932

[29] Löfberg J (2004) YALMIP: A toolbox for modeling and optimization in MATLAB. In: Proceedings of the 2004 IEEE international symposium on computer aided control systems design (CACSD’04), Taipei, 2-4 Sept 2004, pp 284-289

[30] Zimmerman RD, Murillo-Sánchez CE, Thomas RJ (2011) MATPOWER: Steady-state operations, planning and analysis tools for power systems research and education. IEEE Trans Power Syst 26(1):12-19

[31] Billinton R, Li WY (1994) Reliability assessment of electric power systems using Monte Carlo methods. Springer, New York, $352 \mathrm{pp}$

Chengxin LI was born in Chongqing, China, in 1976. He received his Master degree and $\mathrm{PhD}$ degree from Sichuan University in 2003 and 2012, respectively. He is now with the school of Electrical Engineering and Information in Sichuan University. He is currently conducting research as a visiting scholar in the University of Sydney. His research interests include power system planning, power system operation and control, reliability assessment, monitoring and control of power system low frequency oscillation.

Guo CHEN received the $\mathrm{PhD}$ degree from the University of Queensland in 2010. He is now a research fellow at the school of Electrical and Information Engineering in the University of Sydney. His research interests include power system planning, power system security, renewable energy and distributed generation, and planning and control in smart grids.

Junyong LIU received the PhD degree from Brunel University in 1998. He is a Professor and head of the School of Electrical Engineering and Information in Sichuan University. His main research interests include electricity market, power system planning, operation, stability and computer applications. 